\title{
Первая находка псевдотахилитовой брекчии и другие признаки ударного метаморфизма в породах обрамления массива Ярва-варака (Мончегорский рудный район)
}

\author{
Нерович Л.И. ${ }^{1}$, Ильченко В.Л. ${ }^{1}$, Каулина Т.В. ${ }^{1,2}$, Базай А.В. ${ }^{1}$, Кунаккузин Е.Л. ${ }^{1}$, Мудрук С.В. ${ }^{1}$, \\ Борисенко Е.С. ${ }^{1}$, Сосновская М.А. ${ }^{2}$ \\ ${ }^{1}$ Геологический институт КНЦ РАН, Anamumbl,nerovich@geoksc.apatity.ru \\ ${ }^{2}$ Апатиский филиал МГТУ, Апатить
}

\begin{abstract}
Аннотация. Приведены первые данные по исследованию псевдотахилитовой брекчии и планарных деформаций в породах обрамления массива Ярва-варака. В псевдотахилитовой брекчии угловатые обломки гранитного и гнейсового состава, а также кристаллокласты кварца и плагиоклаза погружены в стекловатый цемент. Цемент брекчии при большом увеличении обнаруживает криптокристаллическое строение и по химическому составу близок к составу глиноземистых гнейсов обрамления, особенно к разностям биотитовых и гранат-биотитовых гнейсов с параметрами метаграувакк. По-видимому, образование псевдотахилитовой брекчии связано с шоковым метаморфизмом этих гнейсов при импактном событии. Находка псевдотахилитовой брекчии в породах обрамления интрузива, а также планарного кварца и структуры "kink-banding" в биотите и клиноцоизите в комплексе с данными о сходстве строения разреза и петрографо-геохимических характеристик пород массива Ярва-варака и импактной структуры Садбери предполагает импактное происхождение массива Ярва-варака.

Ключевые слова: Мончегорский рудный район, импактные структуры, псевдотахилит, ударный метаморфизм.

\section{The first find of pseudotachylite breccia and other signs of shock metamorphism in the country rocks of the Jarva-varaka massif (Monchegorsk ore district)}

\author{
Nerovich L.I. ${ }^{1}$, Il'chenko V.L. ${ }^{1}$, Kaulina T.V. ${ }^{1,2}$, Bazay A.V. ${ }^{1}$, Kunakkuzin E.L. ${ }^{1}$, Mudruk S.V. ${ }^{1}$, \\ Borisenko E.S. ${ }^{1}$, Sosnovskaya M.A. ${ }^{2}$ \\ ${ }^{1}$ Geological Institute of Kola Science Centre of RAS, Apatity, nerovich @geoksc.apatity.ru \\ ${ }^{2}$ Apatity branch of MSTU, Apatity
}

Abstract. The first data of the study of pseudotachylite breccia and planar deformations in the country rocks of the Jarva-varaka massif are presented. In pseudotachylite breccia, angular fragments of granite and gneiss composition, as well as quartz and plagioclase crystalloclasts, are immersed in glassy cement. Breccia cement at high magnification reveals a cryptocrystalline structure and in chemical composition is close to that of the host alumina gneisses, especially to the biotite and garnet-biotite gneiss varieties with metagraywacke parameters. Apparently, the formation of pseudotachylite breccia is associated with a shock metamorphism of gneisses during an impact event. Findings of pseudotachylite breccia in the host rocks, as well as planar quartz and the "kink banding" structure in biotite and clinozoisite in combination with similarity of the section structure and the petrographic-geochemical characteristics of rocks of the Jarva-varaka massif and impact the Sudbury structure suggests an impact origin of the Jarva-varaka massif, as well.

Key words: Monchegorsk ore district, impact structures, pseudotachilitis, shock metamorphism.

\section{Введение}

Разрез массива Ярва-варака, расположенного в северной части Мончегорского рудного района, отличается от других палеопротерозойских расслоенных массивов присутствием во всех породах разреза гранофировой составляющей. Подобные разрезы единичны и широко известен только один подобный комплекс - это Садбери, образование которого связывают с импактным событием (Налдретт, 2003). После того, как было установлено сходство петрографического и геохимического состава пород обоих интрузивов (Нерович и др, 2015), была поставлена задача детально изучить обрамление Ярва-вараки. И в ходе полевых работ 2018-2019 гг. впервые в породах обрамле- 
ния массива Ярва-варака была обнаружена псевдотахилитовая брекчия и признаки планарных деформаций в минералах.

\section{Результаты}

Среди пород обрамления массива Ярва-варака развиты преимущественно глиноземистые гнейсы кольской серии и корово-анатектические гранитоиды $\mathrm{S}$ типа. Псевдотахилитовая брекчия наблюдается в пределах северо-восточного фланга массива и узкой полосой протягивается среди глиноземистых гнейсов и гранитов примерно на 50 метров по направлению - С $330-335^{\circ}$. Ширина выходов в С3 направлении уменьшается от 1 м до 20 см. В этом же направлении, как среди обломков, так и среди вмещающих пород возрастает количество массивного кварц-полевошпатового материала. Кроме основной полосы развития брекчии в гнейсах наблюдаются тонкие заливы стекловатого материала.

На настоящий момент более детально изучена относительно более мощная юго-восточная часть площади развития брекчии, где обломки угловатой формы гранитного и гнейсового состава и кристаллокласты кварца и плагиоклаза сцементированы стекловатым цементом (рис. 1). В обломках гнейсов реликты сланцеватости слегка изогнуты, первичная сланцеватость нарушена. Поверхность стекловатого материала гладкая с раковистым изломом, напоминающим поверхность обсидиана. В центре отмечается тонкая вкрапленность сульфидов. Псевдотахилитовая брекчия является характерным объектом импактных структур (Масайтис и др., 1980; French, 1998; Фельдман и др., 2006).

Под микроскопом цемент брекчии имеет оптические характеристики вулканического стекла, без анализатора он бурого цвета с черными пятнами (рис. 2 а, в), с анализатором - изотропный (рис. 2 б, г). В псевдотахилите часто наблюдается так называемая брекчия «грис» или «брекчия
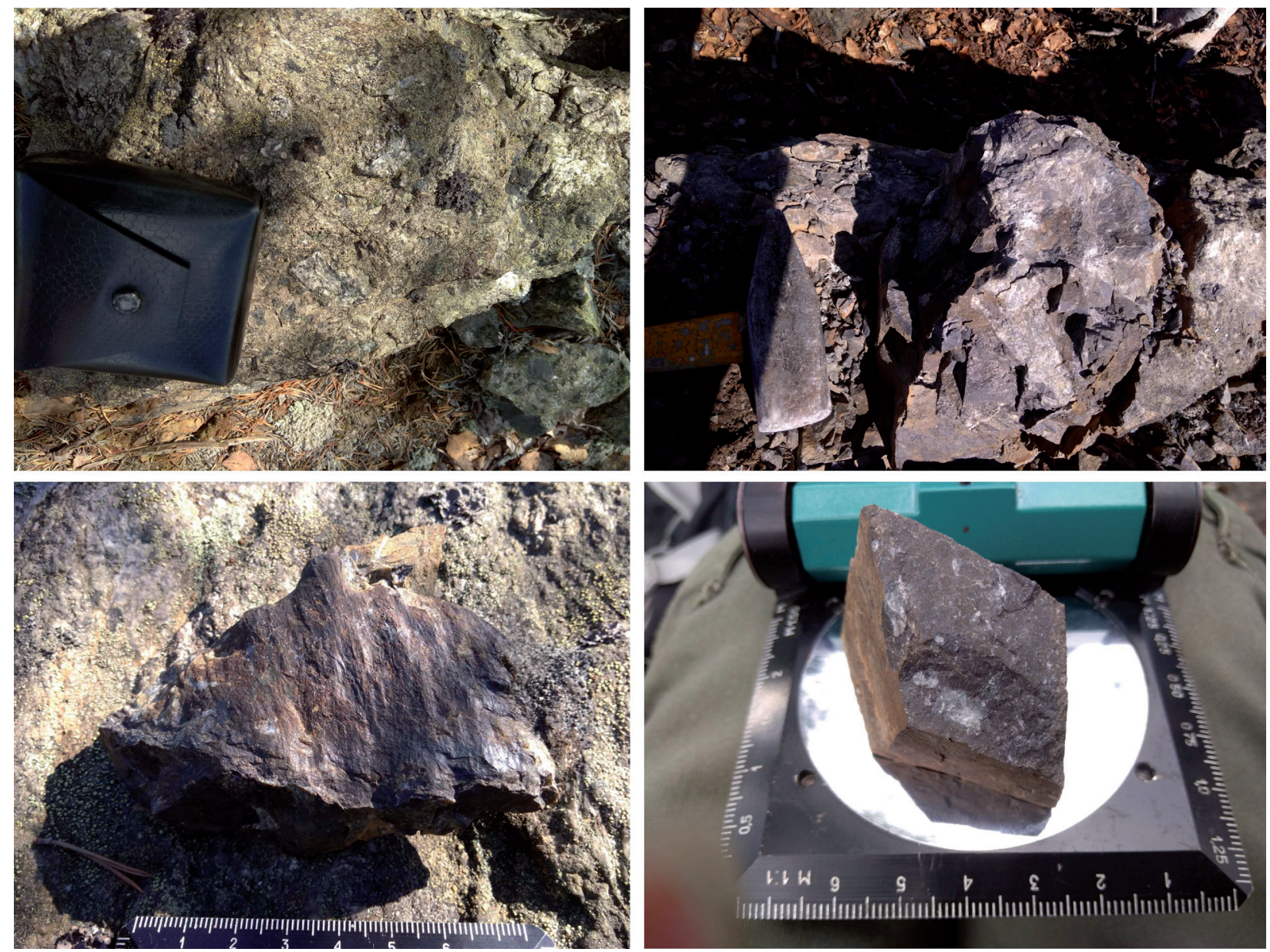

Рис. 1. Полевые фото, обнажение и образцы с юго-восточной части зоны развития псевдотахилитов.

Fig. 1. Field photos, outcrops, and samples from the southeastern part of the pseudotachilite development zone. 

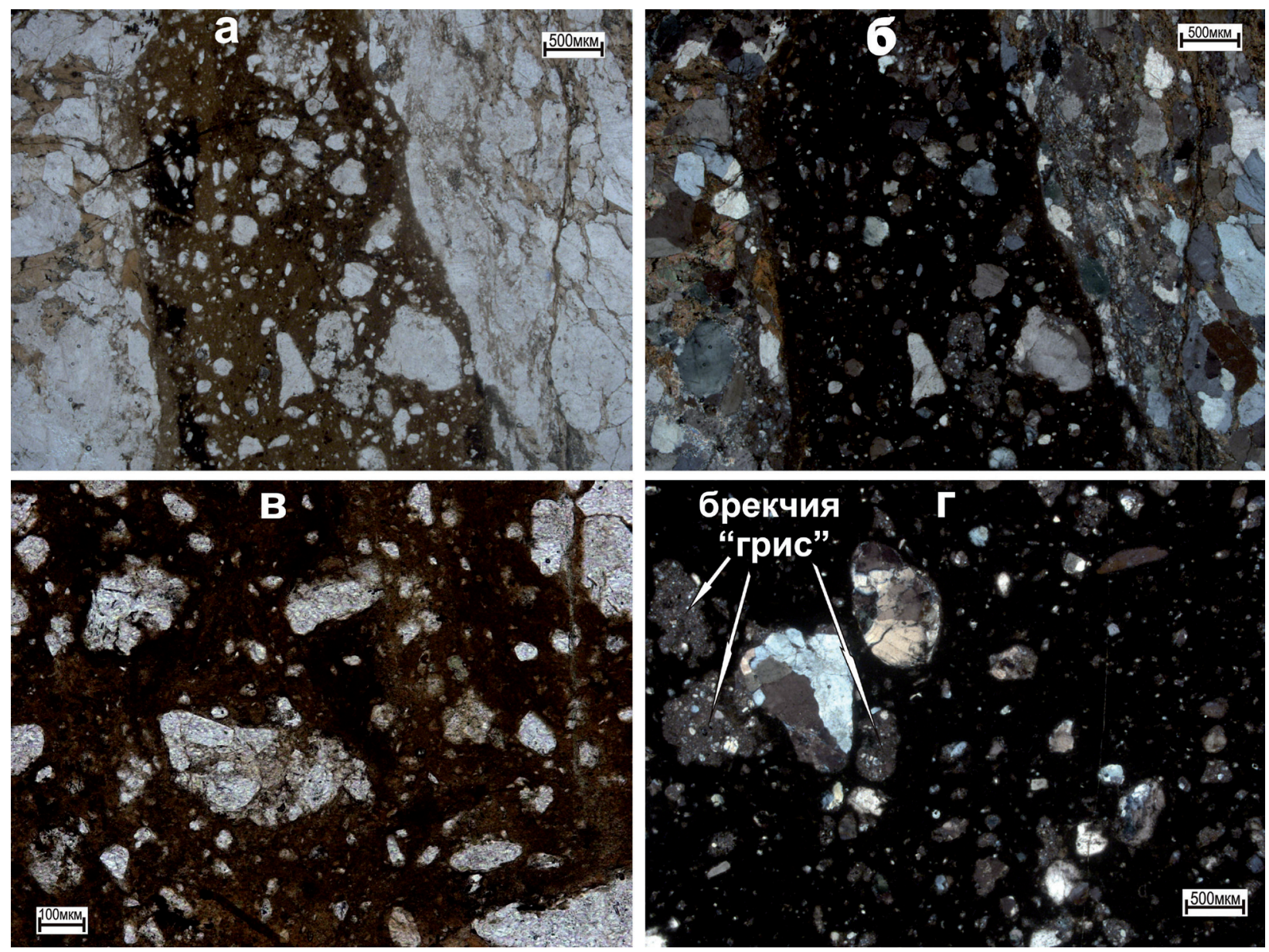

Рис. 2. Микрофото псевдотахилитовой брекчии без анализатора (а, в) и с анализатором (б, г).

Fig. 2. Microphotograph of pseudotachilite breccia without analyzer (a, в) and with analyzer $(б, г)$

в брекчии» (рис. 2 б). Ее образование обычно связывают с неравномерно проявленным дроблением импактированных пород (Фельдман, Глазовская, 2018). Из обнажения в юго-восточной части полосы брекчии отобран материал и определен химический состав ее цемента (без обломков): $\mathrm{SiO}_{2}=58.88, \mathrm{TiO}_{2}=0.81, \mathrm{Al}_{2} \mathrm{O}_{3}=16.46, \mathrm{Fe}_{2} \mathrm{O}_{3}=2.5, \mathrm{FeO}=4.55, \mathrm{MnO}=0.1, \mathrm{MgO}=2.71, \mathrm{CaO}=2.96$, $\mathrm{Na}_{2} \mathrm{O}=3.59, \mathrm{~K}_{2} \mathrm{O}=2.62, \mathrm{CO}_{2}=1.06, \mathrm{P}_{2} \mathrm{O}_{5}=0.11$, все масс. \%. Данный состав характеризуется избыточным содержанием $\mathrm{Al}_{2} \mathrm{O}_{3}$ и близок к составу глиноземистых гнейсов обрамления в целом и, особенно к разностям биотитовых и гранат-биотитовых гнейсов с параметрами метаграувакк. Можно предположить, что образование псевдотахилитовой брекчии связано с шоковым метаморфизмом этих гнейсов при импактном событии. Отличие составов наиболее выражено в повышенном содержании $\mathrm{CO}_{2}$ в цементе брекчии.

При микрозондовом исследовании установлена криптокристаллическая структура цемента брекчии, которая характерна и для других псевдотахилитов мира (рис. 3). На рисунке 3 от 3 а до 3 в показано BSE изображение участка брекчии бурого цвета (см. рис. 2) и видно, что кристаллическое строение проявляется только при очень большом увеличении. Участки брекчии черного цвета отличаются присутствием похожих на микролиты игольчатых выделений, которые видны уже при меньшем увеличении (рис. 3 г-е). Игольчатые выделения обычно имеют разноориентированное положение в матрице брекчии (рис. 3 г, д), но редко отмечается и линейная ориентировка выделений (рис. 3 e). Признаков кристалличности не установлено только в очень мелких заливах брекчии в гнейсах, здесь имеются микрофрагменты с признаками флюидальности (рис. 4).

Важным признаком импактитов считают присутствие планарных элементов в минералах, особенно в кварце. Характерной чертой этих элементов является разнообразие ориентировок в одном и том же кристалле (Osinski, Pierazzo, 2012; Фельдман, Глазовская, 2018). В обрамлении масси- 

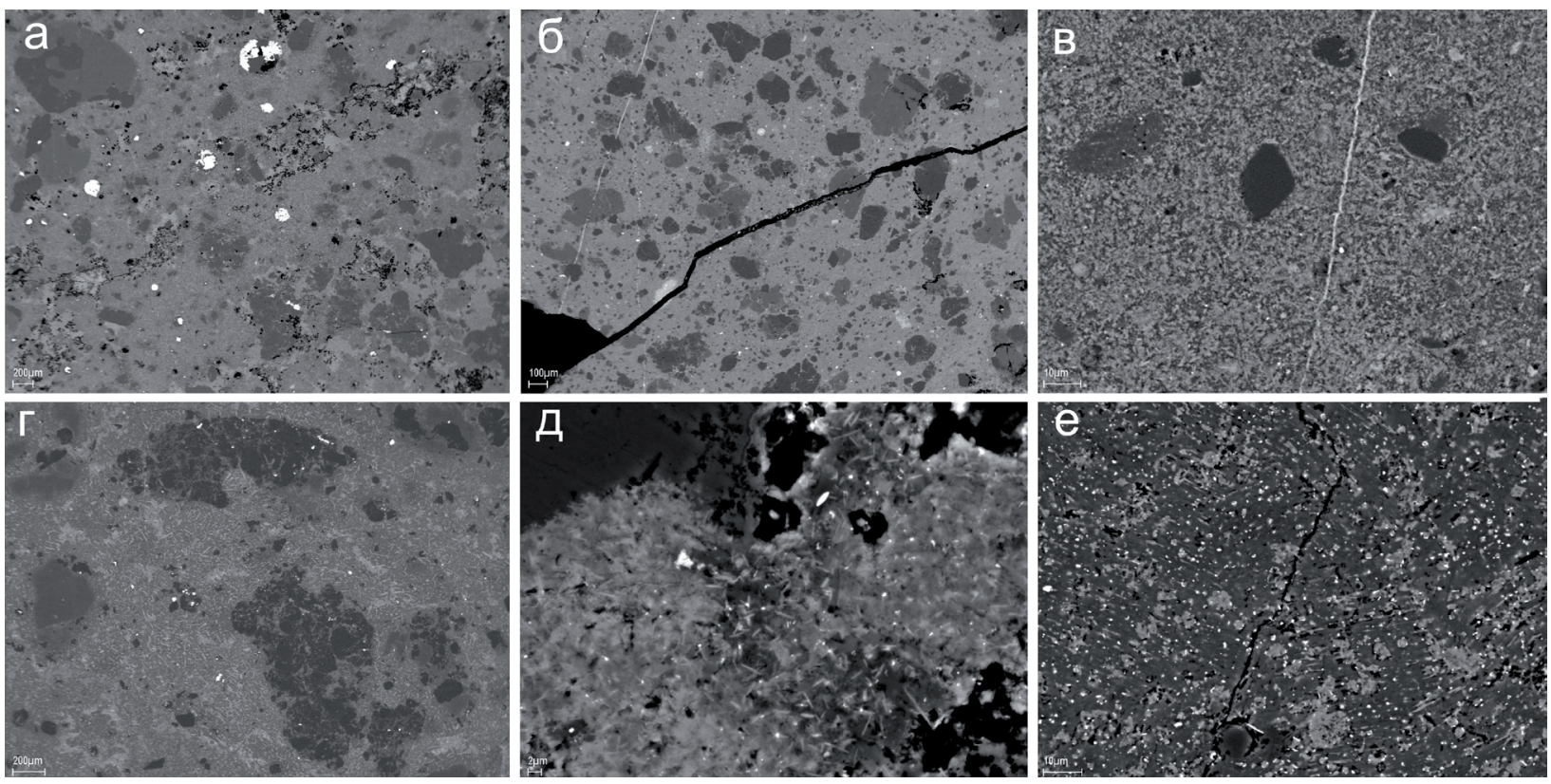

Рис. 3. BSE изображения псевдотахилитовой брекчии. а-в - из участков бурого цвета, г-е - из участков черного цвета.

Fig. 3. BSE-image of pseudotachilite breccia. а-в - from brown plots, г-e - from black plots.

ва Ярва-варака планарные деформации кварца наиболее ярко проявлены в гранитоидах северозападной части площади развития брекчии (рис. 5), возможно из-за большей крупности зерен по сравнению с гнейсами.

Также в биотите и клиноцоизите из гнейсов и гранитоидов обрамления интрузива часто наблюдаются полосы излома и смятия или иначе - структура «kink banding» (рис. 6), характерная для гнейсов основания Садбери (French, 1998). Кроме того, анализ рамановских спектров циркона из мафитовых норитов Ярва-вараки показал признаки преобразования его и минеральных включений в нем в диаплектовые стекла (Каулина и др., 2017).

\section{Выводы}

Находка в породах обрамления массива Ярва-варака псевдотахилитовой брекчии и планарных деформаций минералов в совокупности со сходством строения разреза и петрографо-геохимических
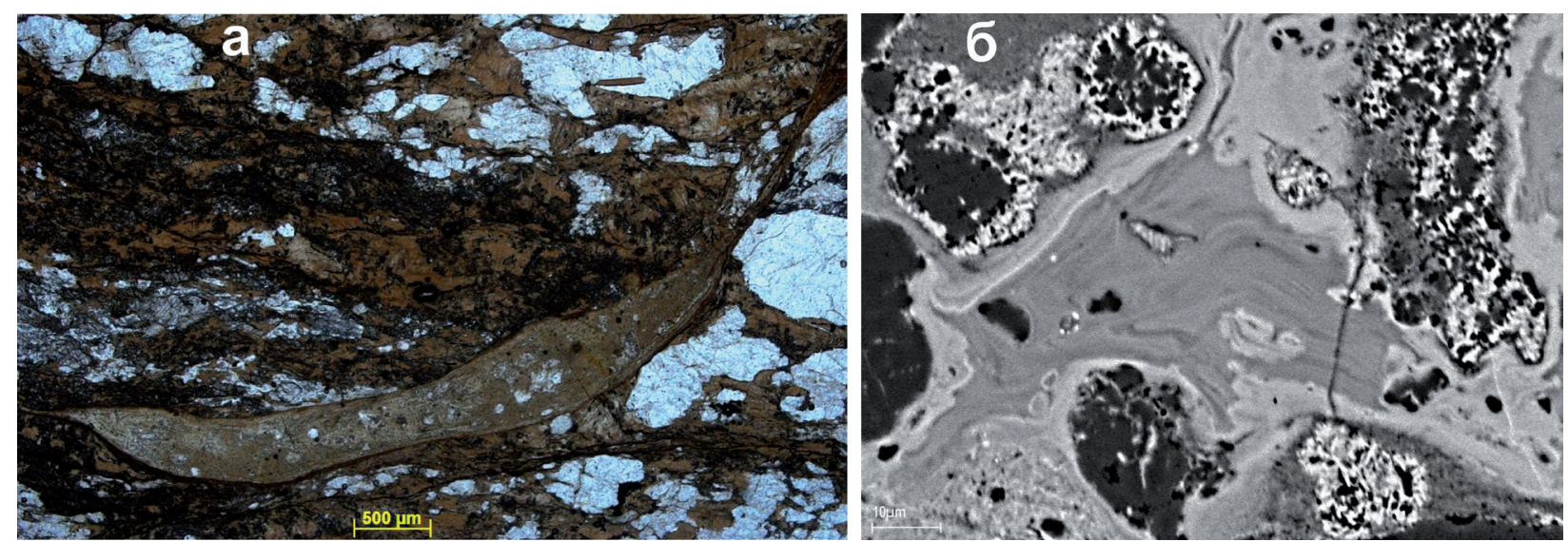

Рис. 4. Микрофото залива псевдотахилитовой брекчии в биотитовых гнейсах (а) и BSE изображение фрагмента залива (б).

Fig. 4. A microphoto of a pseudotachilite breccia bay in biotite gneisses (a) and a BSE image of a bay fragment (б). 

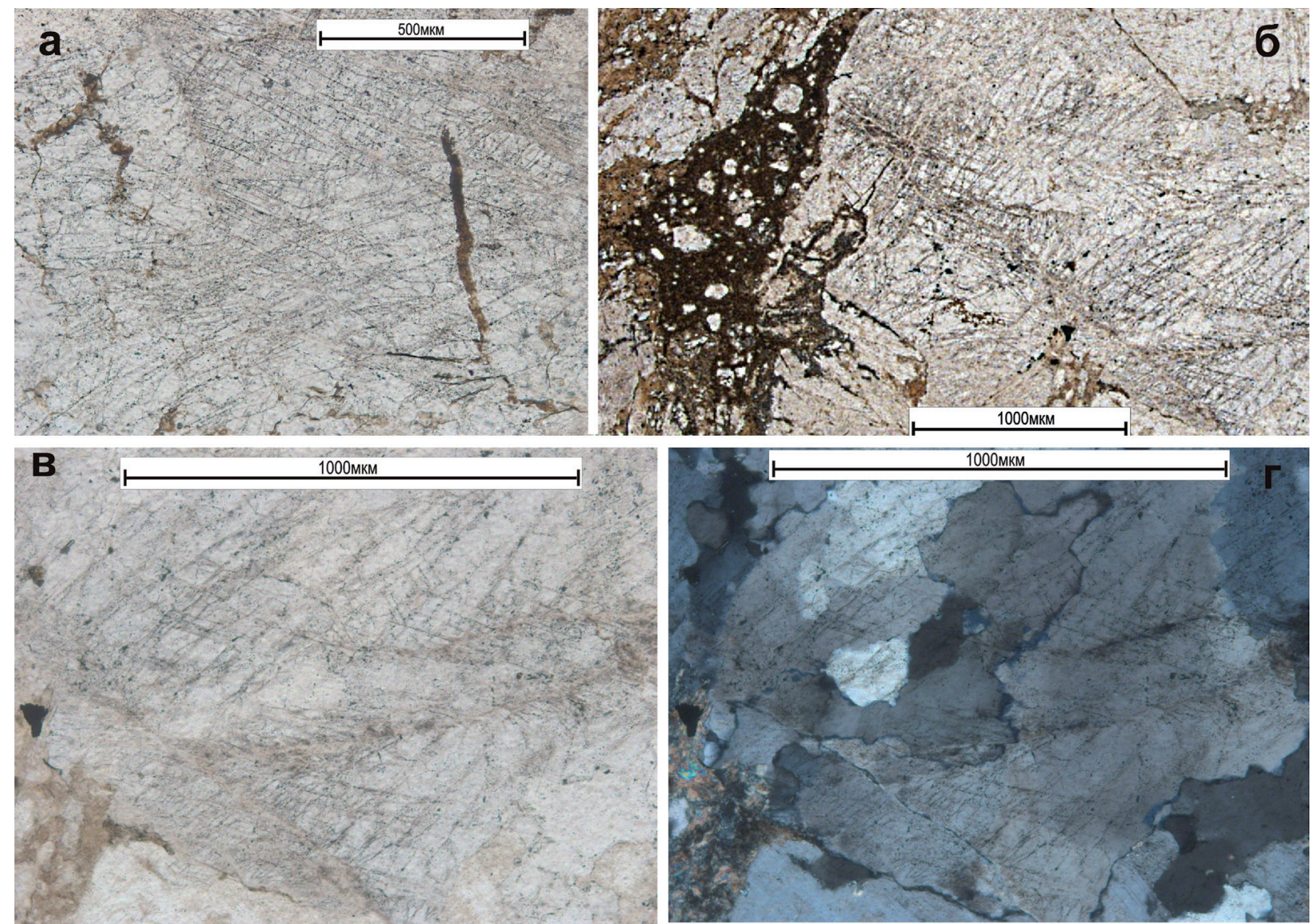

Рис. 5. Планарные деформации в кварце из пород обрамления массива Ярва-варака. а, б, в - без анализатора, г-с анализатором.

Fig. 5. Planar deformations in quartz from the rocks of the framing of the Jarva-varaka massif. a, 6 , в - without an analyzer, $\Gamma-$ with an analyzer.

характеристик пород массивов Ярва-варака и Садбери свидетельствуют о сходстве механизмов их образования, а Садбери на сегодняшний день - общепризнанная импактная структура.
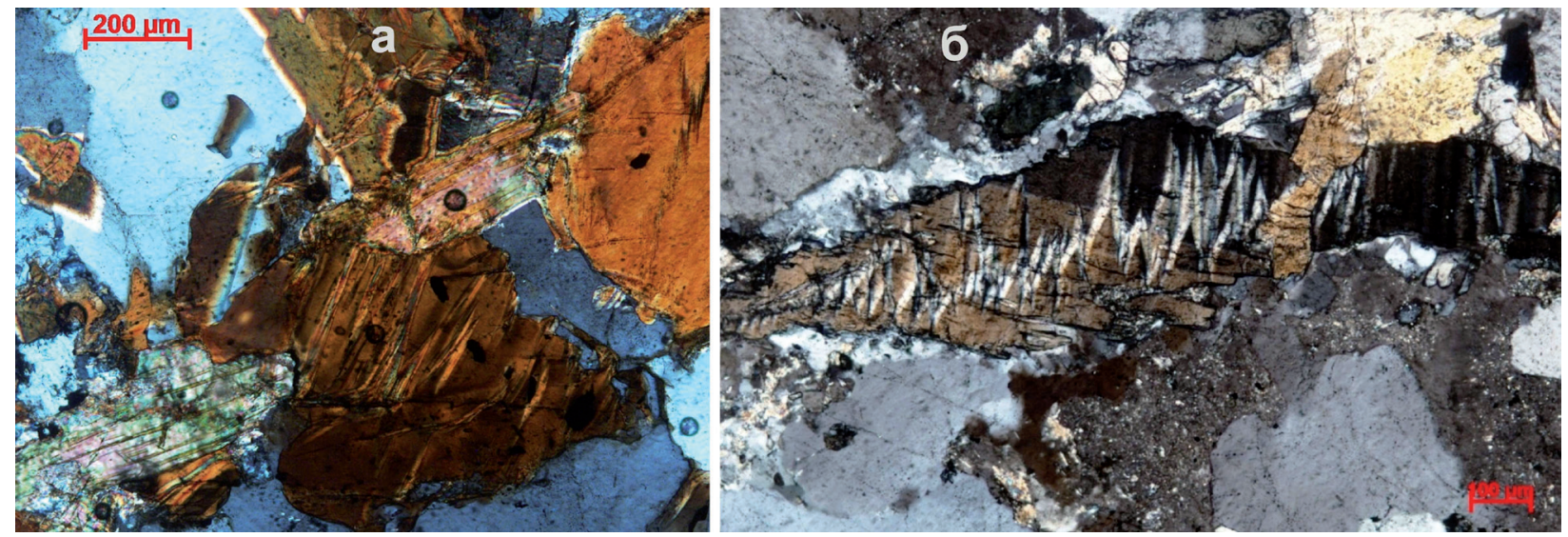

Рис. 6. Клиновидные, зубчатые полосы излома и смятия в биотите и клиноцоизите (структура «kink-banding») из гнейсов и гранитоидов обрамления массива Ярва-варака, с анализатором.

Fig. 6. Wedge-shaped, dentate strips of fracture and crushing in biotite and clinokoizite ("kink-banding" structure) from gneisses and granitoids of the framing of the Jarva-varaka massif, with an analyzer. 


\section{Благодарность}

Авторы благодарят М.В. Наумова, Н.П. Виноградову и Л.И. Константинову за помощь в работе. Работа выполнена в рамках темы НИР № 0226-2019-0053.

\section{Литература}

1. Каулина Т.В., Нерович Л.И., Бочаров В.Н., Лялина Л.М., Ильченко В.Л., Кунаккузин Е.Л., Касаткин И.А. Рамановская спектроскопия импактного циркона из расслоенного массива Ярва-варака (Мончегорский рудный район, Кольский полуостров) // Вестник МГТУ. 2017. Т. 20. № 1/1. С. 72-82. DOI:10.21443/1560-9278-2017-20-1/1-72-82.

2. Масайтис В.Л., Данилин А.Н., Мащак М.С., Райхлин А.И., Селивановская Т.В., Шаденков Е.М. Геология астроблем. Л. Изд-во: Недра. 1980. 231 с.

3. Налдретт А.Дж. Магматические сульфидные месторождения медно-никелевых и платинометальных руд. Санкт-Петербург. Изд-во: СПбГУ. 2003. 487 с.

4. Нерович Л.И., Баянова Т.Б., Кунаккузин Е.Л., Базай А.В., Некипелов Д.А. Новые результаты геологопетрографического и геохимического изучения расслоенного массива Ярва-варака, Мончегорский рудный район // Труды Ферсмановской научной сессии ГИ КНЦ РАН. 2015. Т. 12. С. 141-146.

5. Фельдман В.И., Сазонова Л.В., Козлов Е.А. Ударный метаморфизм некоторых породообразующих минералов (экспериментальные и природные данные) // Петрология. 2006. Т. 14. № 6. С. 576-603.

6. Фельдман В.И., Глазовская Л.И. Импактитогенез: учебное пособие. М. Изд-во: КДУ. 2018. 151 с.

7. French B.M. Traces of Catastrophe: A Handbook of Shock-Metamorphic Effects in Terrestrial Meteorite Impact Structures. LPI Contribution № 954, Lunar and Planetary Institute, Houston. 1998. 120 pp.

8. Osinski G.R., Pierazzo E. Impact cratering: Processes and products. John Wiley \& Sons, 2012. 330 p. 